\title{
NOVAS PERSPECTIVAS PARA A EDUCAÇÃO DE JOVENS E ADULTOS: UM ESTUDO ANDRAGÓGICO NO CURSO TÉCNICO DE RECURSOS PESQUEIROS
}

\author{
L. do N. Mendes ${ }^{1}$ e P. C. M. Chagas ${ }^{2}$ \\ ${ }^{1,2}$ Instituto Federal de Educação, Ciência e Tecnologia do Rio Grande do Norte \\ luciana.mendes@ifrn.edu.br ${ }^{1}$
}

Artigo submetido em outubro/2011 e aceito em março/2013

\section{RESUMO}

Os cursos técnicos do Instituto Federal de Educação, Ciência e Tecnologia do Rio Grande do Norte-IFRN são distribuídos nas modalidades integrado, subsequente e EJA, este último para a inserção daqueles que estão há anos fora da sala de aula e apresentam dificuldades no processo de aprendizagem. O presente estudo nos mostra um relato de experiências com pessoas jovens e adultas, sob a perspectiva de abordar uma realidade que envolve alunos em ciclos de vida e faixa etárias similares aos sujeitos da modalidade EJA, o que foi presenciado na modalidade subsequente do curso técnico em Recursos Pesqueiros. O objetivo deste trabalho é analisar a prática andragógica, isto é, a arte de educação voltada a adultos. Através da aplicação de um questionário a esses alunos foram obtidos resultados que puderam explicar melhor os motivos das dificuldade no processo de aprendizagem, e que nos aponta a necessidade de se pensar práticas de ensino com base na andragogia.

PALAVRAS-CHAVE: Andragogia, Educação de Jovens e Adultos, Aprendizagem.

\section{NEW PERSPECTIVES TO THE YOUTH AND ADULT EDUCATION: AN ANDRAGOGICAL STUDY IN THE TECHNICAL COURSE OF FISHERY RESOURCES}

\section{ABSTRACT}

The technical courses of Instituto Federal de Educação, Ciência e Tecnologia do Rio Grande do Norte-IFRN are distributed in the modalities of integrated, subsequent and youth and adult education (YAE) courses, the last for the insertion of people who are far from school for many years and present some difficulties in the learning process. The present study has shown a report of experiences with young and adult people, under the perspective of approaching a situation which involves students in life cycles, and age times similar to the subjects of YAE classification, for these ones present a delay in the answers to the teaching in the classroom. Our goal here is to analyze the andragogical practice, in other words, the art of education targeted to adults, specifically related to the students of the technical course of Fishery resources. Through the application of a questionnaire, some results were obtained that could explain in a better way the reasons for that difficulty in the learning process. It shows us the need of thinking of teaching practices based on andragogy.

KEY-WORDS: andragogy, youth and adult education (YAE), learning. 


\section{NOVAS PERSPECTIVAS PARA A EDUCAÇÃO DE JOVENS E ADULTOS: UM ESTUDO ANDRAGÓGICO NO CURSO TÉCNICO DE RECURSOS PESQUEIROS}

\section{INTRODUÇÃO}

O curso técnico em Recursos Pesqueiros do Instituto Federal de Educação, Ciência e Tecnologia do Rio Grande do Norte - IFRN, instalado no Campus Macau, no município de mesmo nome, teve início de suas atividades em setembro de 2009.

Expõe-se no presente texto o desenvolvimento e análise de práticas de ensino e aprendizagem, vivenciadas com turmas do Curso de Recursos Pesqueiros, na perspectiva de fomentar reflexões sobre as experiências com o ensino técnico e as estratégias com as quais os alunos desta modalidade apreendem e produzem conhecimentos.

Os cursos técnicos oferecidos no IFRN são distribuídos nas modalidades integrado, subsequente e Proeja (Programa Nacional de Integração da Educação Profissional com a Educação Básica na Modalidade de Educação de Jovens e Adultos).

Segundo Brasil (2010), os cursos técnicos, na modalidade subsequente, dizem respeito à oferta de ensino técnico, profissionalizante, aos alunos que já concluíram o ensino médio, com cursos variando de um ano e meio a dois anos de duração.

O PROEJA objetiva oferecer a jovens e adultos trabalhadores oportunidades de escolarização que aliam a educação básica à educação profissional (GOMES; ANGELO; MOURA, 2007).

A novidade do PROEJA é a integração entre formação geral e formação profissional na modalidade EJA (LOPES; VALENTIM, 2010).

No campus Macau, no ano de 2009 ingressou no referido curso, um total de 80 alunos (divididos em 2 turmas), na modalidade subsequente, turno vespertino, e 47 alunos (divididos em 2 turmas), na modalidade Proeja, turno noturno.

Todavia, ao longo das aulas ministradas, observou-se dificuldade de aprendizado nas disciplinas técnicas diretamente relacionadas ao curso técnico em Recursos Pesqueiros, em uma das turmas da modalidade subsequente, turno vespertino. A turma apresentava diferença em suas faixas etárias, possuindo alunos entre 18 anos e 60 anos.

Aos poucos, esses mesmos alunos citaram que há anos haviam terminado o ensino médio (a grande maioria ex-alunos de escolas públicas deste município), cujo processo educativo ainda apresenta falhas, o que dificultou, inicialmente, a compreensão e assimilação de algumas das disciplinas técnicas.

É sabido que a dificuldade maior no processo de aprendizagem é mais comum entre alunos da modalidade PROEJA do que da subsequente que, muitas vezes, tão logo concluem seu ensino médio, investem na carreira técnica.

Contudo, a situação com essa turma vespertina foi diferente, uma vez que em seu processo de assimilação das disciplinas técnicas do curso, como exemplo a disciplina de Meteorologia, que se baseia na Física, Química, Matemática e Geografia para o aprendizado teórico-prático sobre a interação ar-água-terra apresentou dificuldade, sendo necessário repetir alguns tópicos mais de três vezes até a total assimilação por parte dos alunos, de forma simétrica, uma vez que muitos deles ou não recordavam as disciplinas do ensino propedêutico, ou alegavam não terem visto isto em sala de aula. 
Para a identificação das dificuldades dos processos de aprendizagem entre alunos do curso técnico em Recursos Pesqueiros, modalidade subsequente, daqueles da modalidade EJA, faz necessário um acompanhamento não apenas de forma pedagógica, mas também de psicossocial para, assim, identificar os reais problemas em seu processo de aprendizado, uma vez que nem sempre estes estão atrelados ao processo de ensino, mas também às questões culturais, sociais, econômicas, e motivacionais, o que justifica a realização deste estudo.

Portanto, caracteriza como ponto a ser pesquisado o processo de aprendizagem dos alunos do curso técnico em Recursos Pesqueiros, da modalidade subsequente, considerando principalmente as dimensões psicológicas, culturais, sociais e o ambiente escolar antecessor ao curso em questão.

\section{CAMINHOS METODOLÓGICOS}

A primeira etapa consistiu da apresentação do estudo à turma a ser pesquisada, através de explanação sobre as observações, e entrevistas a serem realizadas na segunda etapa do estudo.

A segunda etapa foi a realização de entrevistas aos alunos, de forma oral, guiadas por perguntas que continham aspectos relacionados ao ensino e aprendizagem, como apresentadas abaixo:

1) O que você acha das suas experiências vividas na escola?

2) Antes de estudar aqui, no IFRN, você estudou onde? Há quanto tempo tinha deixado de estudar ou ingressou assim que concluiu o Ensino Fundamental?

3) O que você acha dos estudos?

4) Para você, o que significa estudar e aprender?

5)O que faz você se sentir motivado ou empolgado ou interessado para estudar?

6) Você acha que tem dificuldades para aprender? Quais seriam essas dificuldades?

7) O que faz você gostar da escola e dos conteúdos que aprende?

Os comportamentos dos alunos, relacionamento interpessoal entre alunos e professor eram observados frequentemente, bem como a atenção as aulas.

\section{OLHARES, VOZES, PERCEPÇÕES E RESULTADOS DA EXPERIÊNCIA ANDRAGÓGICA}

No semestre 2009.2, duas turmas foram formadas no curso técnico em Recursos Pesqueiros. As turmas foram divididas em 1RP Sbs 1V e 1RP Sbs 2V, porém na turma 2V, objeto da pesquisa, quando foram iniciadas as atividades letivas do Campus Macau, observou-se o ritmo desta turma em relação à anterior, e a partir de então, tornaram-se claros alguns entraves na assimilação de alguns assuntos, e provavelmente o fator faixa etária, aliado ao tempo fora das salas de aulas, e longe da obtenção de conhecimentos atualizados, tornaram a turma com um ritmo distinto ao aprendizado, uma vez que na turma $1 \mathrm{~V}$ a faixa etária é mais uniforme (18 a 25 anos e raros entre 25 a 30 anos).

A partir dessas observações, resolveu-se realizar um estudo andragógico, que segundo Gatti (2005), Andragogia é uma ciência, a arte da educação de adultos. Sua definição no grego é andros - adulto e gogos - educar. Uma das particularidades dessa ciência é entender a motivação das pessoas e o que está por trás da aprendizagem, e assim analisar melhor de que forma a idade, o tempo fora de sala de aula, e quem sabe outros elementos sócioculturais podem 
interferir na assimilação de assuntos técnicos, ligados diretamente a disciplinas propedêuticas já vistas por esses alunos.

Os estudos sobre Andragogia começaram por Linderman (apud. Gatti, 2008, p.14) que escreveu:

[...]Nosso sistema acadêmico se desenvolveu numa ordem inversa: assuntos e professores são os pontos de partida, e os alunos são secundários...O aluno é solicitado a se ajustar a um currículo pré-estabelecido... Grande parte do aprendizado consiste na transferência passiva para o estudante da experiência e conhecimento de outrem. (Gatti, 2005, p.14)

Estudos andragógicos podem ainda ser considerados relativamente novos no mundo, quando é citado que

[...] a vida adulta começou a ser estudada em um período relativamente recente, embora não se possa negar que as pesquisas psicológicas foram, a princípio, realizadas com adultos e não com crianças, adolescentes ou pessoas idosas. Essas pesquisas faziam parte de estudos sobre as funções psíquicas, os quais seguiam o enfoque da Psicologia Geral e tinham um ponto de vista distante da Psicologia do Desenvolvimento. Nesses trabalhos, o estudo do ser humano tinha como base o modelo do adulto, deixando-se de lado as suas peculiaridades, o que é próprio do período adulto do desenvolvimento. Não eram estudadas as diferenças dos adultos de diferentes idades nem as que os separam dos adolescentes, das crianças e dos idosos. (Griffa, 2009, p.83).

Portanto, é importante que as instituições públicas e privadas abram suas portas a esse público que a cada dia busca uma nova valorização de vida, através do ensino, do aprendizado, porém adequando-se ao seu perfil de forma gradativa.

Desafios existem como o déficit no processo de ensino e aprendizagem visto em muitas escolas públicas deste país, ocasionando em muitos cursos, como no caso dos técnicos, uma demora na resposta de alunos com idade considerada mais avançada, ao aprendizado visto em sala de aula.

Nesse contexto, surge

[...] a dificuldade em se distinguir as etapas posteriores à adolescência por causa da impossibilidade de se determinar limites e momentos-chave comuns a todas as pessoas no transcurso desse ciclo vital. Sugerem as seguintes distinções: juventude ou segunda adolescência (18 a 25 anos); - vida adulta jovem ou precoce (25 a 30 anos); - vida adulta média (30 a 50 anos), amadurecimento adulto, crise da meia-idade; - vida adulta tardia ou segunda vida adulta (50 a 65 anos). (Griffa, 2009, p.93).

Baseando-se nestas constatações, é possível observarmos e delimitarmos grupos de alunos da turma em estudo do curso técnico em Recursos Pesqueiros, escolhidos para a referida pesquisa, nas modalidades acima citadas, distribuindo-os por faixas etárias, como seguem:

- juventude ou segunda adolescência (18 a 25 anos): 11 alunos

- vida adulta jovem ou precoce ( 25 a 30 anos): 5 alunos

- vida adulta média (30 a 50 anos), amadurecimento adulto, crise da meia-idade: 5 alunos

- vida adulta tardia ou segunda vida adulta (50 a 65 anos): 1 aluno.

Em 2009, quando foi iniciada a disciplina de Meteorologia, foram utilizados para todos os alunos modelos representativos do Planeta Terra, da Lua e do Sol com o auxílio de bolas de 
isopor, papel celofane, algodão para representar o sistema solar e assim explicar de que forma ocorrem os fenômenos atmosféricos.

Utilizou-se este artifício após ser constatada uma demora na resposta de aprendizados desses alunos, e para estabelecer uma sequencia semelhante aos conteúdos, a metodologia foi utilizada em ambas as turmas.

Os alunos começaram a demonstrar uma melhor resposta quando se utilizaram as maquetes, e também a colagem da sequência das camadas atmosféricas nas paredes da sala de aula, visto que os alunos esqueciam com facilidade o assunto abordado.

Um dos fatores relacionados a esse esquecimento pode ter relação com o fato de muitos serem egressos de escolas públicas do município de Macau com déficit na educação das matérias propedêuticas, base da disciplina de Meteorologia. Por exemplo, quando se chegou ao assunto sobre a camada atmosférica chamada "Ionosfera", e os fenômenos ópticos e elétricos que ocorrem nela, os alunos ficaram calados quando foi citado que nessa camada ocorrem choques de íons. Foi a eles perguntado: "vocês lembram o que são íons?". E, a resposta foi quase unânime: "professora, se vi não me lembro", "o professor não deu esta aula não", dentre outras respostas.

Nas primeiras aulas, após os professores terem sido apresentados, aos poucos os alunos foram abrindo histórias sobre suas vidas, e citando sua origem, o envolvimento ou não com sua comunidade, ou melhor, a identidade de pertencimento de um local, e basicamente, essa turma se não provém diretamente de uma comunidade pesqueira, relatou que seus pais, seus avós foram pescadores, ou exerceram atividade relacionada ao setor.

Ao analisar os questionários aplicados com 25 alunos, de forma coletiva, foi constatada uma relação direta a dificuldade em acompanharem os assuntos, devido, provavelmente a suas origens educacionais, à falta de incentivo mais sistemático para a aprendizagem ou a escola não dispunha de matérias e equipamentos, dificultando a abordagem de assuntos relacionados às ciências, ou ainda a carga horária muito alta desses professores.

O gráfico abaixo retrata a relação ao tempo de afastamento da escola, e a origem da escola, apresentando a quantidade de alunos provenientes de escola pública e de escola particular:

\section{Total}

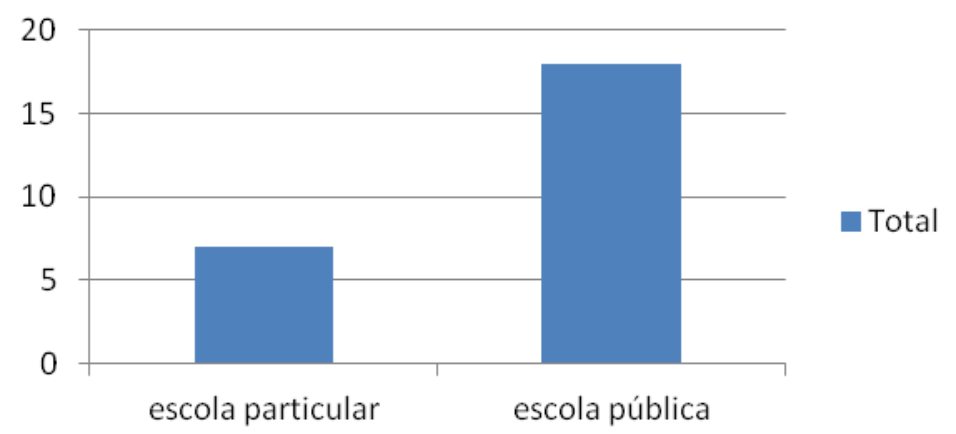

Figura 01: relação dos alunos de origem particular e pública.

É interessante salientar que, do total de 25 alunos entrevistados, há uma disparidade em relação ao tempo de afastamento da sala de aula, como relatados por eles. Por exemplo, a turma 
apresentou alunos que finalizaram o ensino médio há um ano, como também aqueles que pararam os estudos há 13, 20 ou até 25 anos.

Mas, é interessante salientar que há um aluno idoso na turma, que nunca parou os estudos, porém este é um caso, à parte, de motivação, interesse e participação, uma vez que ele já possui graduação, já lecionou e faz do estudo um momento de engrandecimento de seus conhecimentos.

É possível que o tempo entre o final do ensino médio, bem como o tipo de escola (se pública ou particular) tenha influenciado diretamente no processo de assimilação das disciplinas técnicas, uma vez que não sabemos de que forma as disciplinas propedêuticas eram repassadas aos alunos, se de forma motivacional ou não.

Salienta-se, por meio de estudos e índices avaliativos, então, que a qualidade das escolas do estado do Rio Grande do Norte, principalmente as do município de Macau e microrregião salineira, ainda não oferecem um ensino propedêutico de qualidade, prejudicando o conhecimento das matérias básicas a esses alunos, que buscam num curso técnico profissionalizante um engrandecimento em sua qualidade de vida.

Baseado nas respostas dos alunos, através da entrevista coletiva são apresentados abaixo, alguns trechos de suas falas reais que representam tais questões:

\section{“O que voce acha dos estudos?"}

Aluno A: "O alicerce fundamental para a vida profissional".

Aluno C: "Base de tudo para convívio com a sociedade".

Aluno G: "Aquisição de conhecimento geral (ampliação da visão de vida)."

"Para você, o que significa estudar e aprender?"

Aluno H: "Faz crescer e que ninguém tirará (tanto crescimento pessoal como profissional)".

Alunos P e R: "A única saída para melhorar de vida.

Aluno J: "Adquirir conhecimentos".

"O que faz você se sentir motivado ou empolgado ou interessado para estudar?"

Aluno C: "Curiosidade, vontade de aprender".

Aluno E: "Motivador - quem ensina; aulas de campo incentivam".

Aluno F: "Crescer na vida".

"Voce acha que tem dificuldades para aprender?

"Quais seriam essas dificuldades?".

Alunos A e B: "Tenho dificuldade dependendo do professor."

Aluno E: "Não tenho dificuldade"

Aluno X e Y: "Depende de quem está passando a matéria para o aluno. Não gosta que jogue só a matéria, mas explique e envolva o aluno.

"O que faz você gostar da escola e dos conteúdos que aprende?"

Aluno G: "Ensino de qualidade".

Alunos I, K e M: "A afinidade com a área de estudo em Recursos Pesqueiros".

Aluno N, Q: "Professores".

Baseada nessas observações cabe aqui o enfoque dos métodos globalizados, que cita que [...] a maioria das formas de ensinar que se aplica hoje o que podemos considerar métodos globalizados tem relação com modelos criados em diferentes momentos do século XX. Muitos dos métodos utilizados atualmente são uma evolução direta daqueles modelos, enquanto outros reúnem e integram elementos de diversos 
modelos. [...] historicamente, os métodos globalizados nascem quando o aluno é considerado o protagonista do ensino, isto é, quando o fio condutor da educação desloca-se das matérias para os alunos e, assim, para suas capacidades, seus interesses e motivações. (Zabala, 2002, p.196).

A figura 02 retrata atividade desenvolvida em sala de aula, durante aulas da disciplina de Meteorologia, ao serem utilizadas bolas de isopor e papel celofane, como forma de aprendizado por parte dos alunos, com o uso de maquetes, corroborando o que foi citado por Zaballa (2002), quando relaciona o deslocamento da matéria para o aluno, desenvolvendo o intelecto destes, e indo mais além, motivando-os a pensarem, a se envolverem e fazerem parte do meio onde se encontram - a sala de aula.

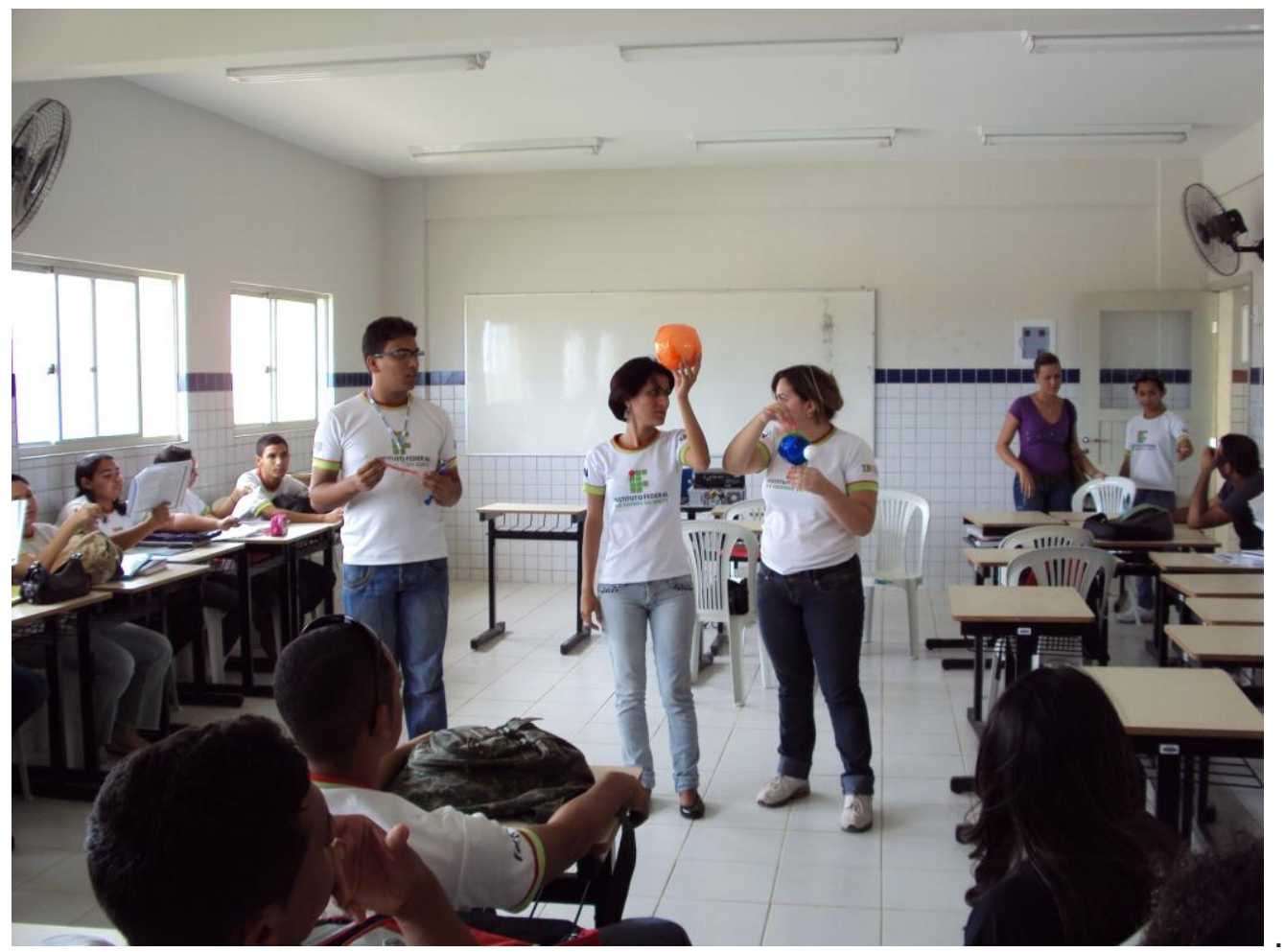

Figura 02: atividade prática na disciplina de Meteorologia - aula sobre camadas atmosféricas a partir do uso de recursos didáticos.

Mesmo sem o conhecimento anterior desses métodos, e sendo eles focados à educação infantil, ao ensino fundamental e ao ensino médio, foi possível, ao conhecer os alunos, aprofundar as atividades baseadas nas formas explicitadas através dos 4 métodos globalizados divididos pelo autor, os quais dizem que:

[...] os centros de interesse de Declory partem de um núcleo temático motivador para os alunos e, seguindo os processos de observação, associação e expressão, integram conteúdos de diferentes áreas de conhecimento. O método de projetos de Kilpatrick consiste, basicamente, na elaboração de algum objeto ou na confecção de uma montagem (uma máquina, um audiovisual, uma estufa, uma horta escolar, um jornal, etc.). A investigação do meio do MCE (Movimento de Cooperazione Educativa de Itália) tenta fazer com que as crianças construam o conhecimento através da sequência do método científico (problemas, hipóteses, confirmação). Os projetos de trabalhos globais, com o objetivo de conhecer um tema que os alunos escolheram, propõem que é preciso elaborar um dossiê ou 
uma monografia como resultado de uma pesquisa pessoal ou de grupo. (Zabala, 2002, p.197)

Zabala (2002) cita que a ideia básica de projetos de Kilpatrick é mobilizar a aprendizagem a partir da necessidade de elaborar algo que continua sendo uma das melhores maneiras de promover a motivação e a significatividade das aprendizagens.

Para o melhor aprendizado da disciplina de Marinharia e Confecção de Apetrechos de Pesca, onde um dos tópicos é a caracterização de embarcações pesqueiras, a atividade realizada de construção de uma maquete de forma compartilhada (em grupo) rendeu aos alunos um bom aprendizado, principalmente em se tratando da turma em estudo, conforme figura abaixo:

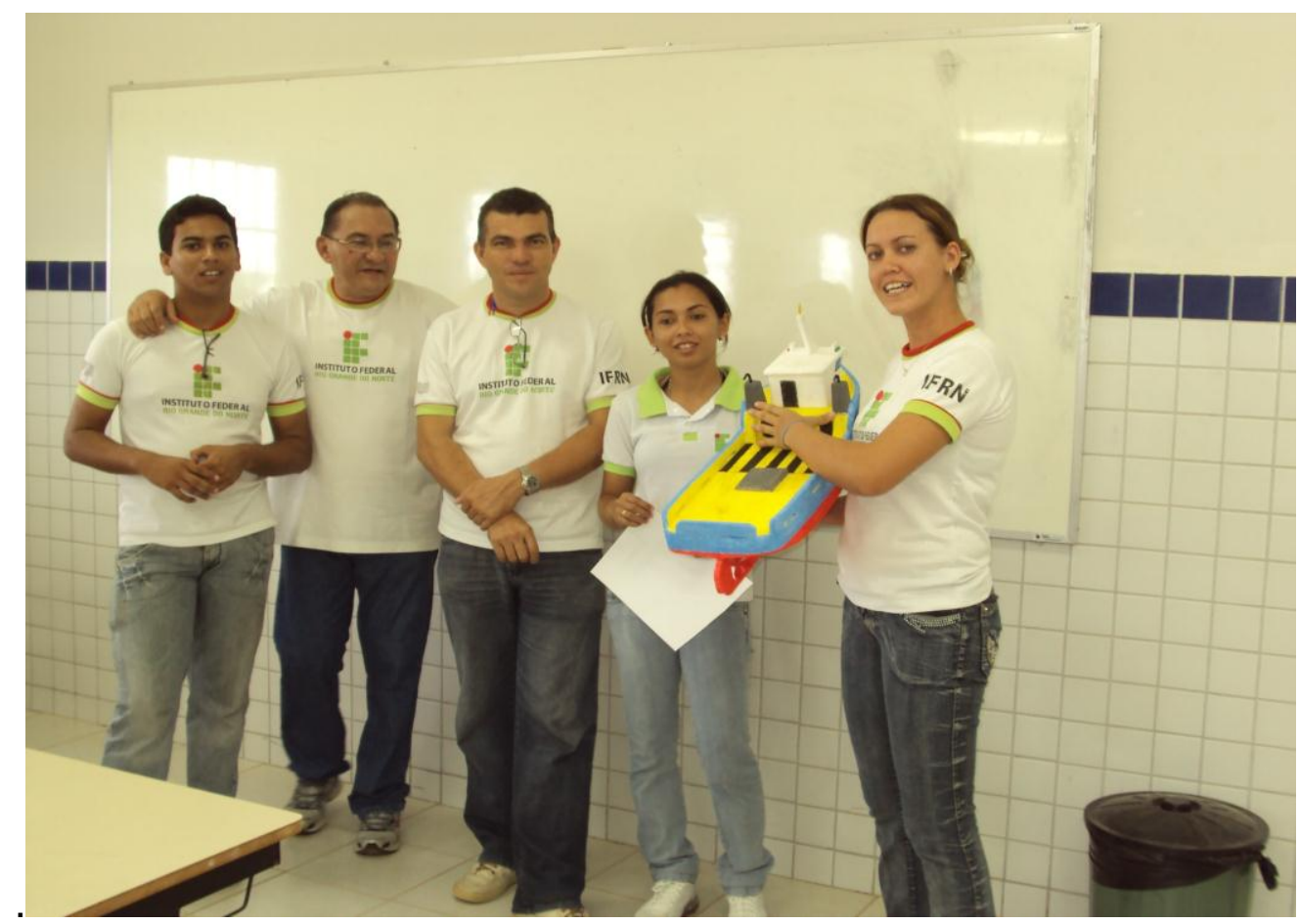

Figura 03: atividade de construção e apresentação de uma maquete de uma embarcação pesqueira.

Vale salientar que outras disciplinas, tais como Gestão e Extensão Pesqueira, e Piscicultura, onde os alunos encenaram em sala de aula possíveis atividades práticas do cotidiano do campo técnico, como a utilização do Diagnóstico Rural Participativo - DRP (figura 03), como forma de atividade avaliativa, o rendimento foi bastante promissor, e que pode estar alencada no método de Declory, que, segundo Zabala (2002), parte de um núcleo temático motivador para os alunos e, seguindo os processos de observação, de associação e de expressão, integram conteúdos de diferentes áreas de conhecimento. 


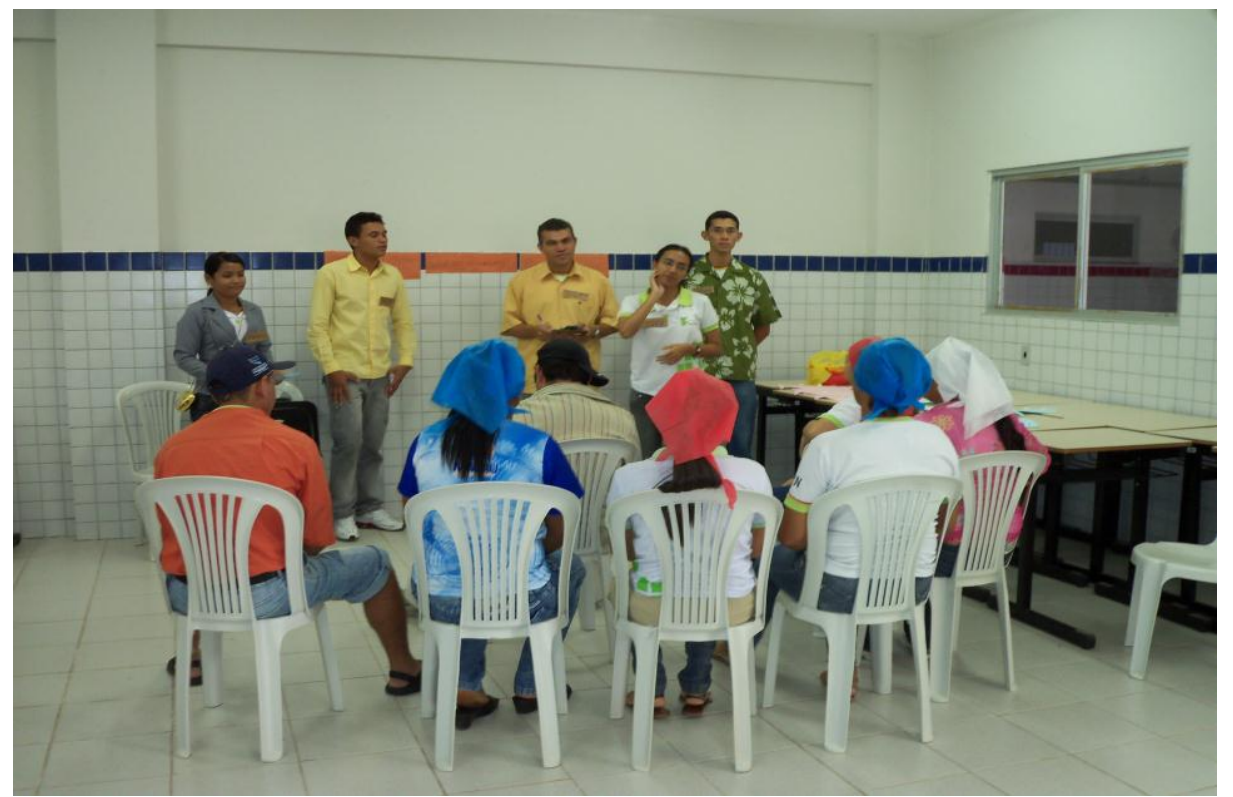

Figura 04: atividade prática do uso de aplicação do Diagnóstico Rural Participativo - DRP, como atividade avaliativa em sala de aula.

Outras associações, baseadas nesses métodos, até então desconhecidos também pelos alunos, os envolveram nas atividades pelo método da investigação do meio, através da apresentação de seminários, elaboração de roteiros de suas apresentações, pesquisas dirigidas realizadas na biblioteca do campus.

O objetivo foi o de despertar neles sua interação e gosto pelos livros, e uma busca pelo conhecimento defasado há anos, ao se depararem com livros atuais e de qualidade, além de relatórios de visitas técnicas ou aulas de campo, e também os projetos de trabalhos globais, uma vez que estes alunos iniciaram sua preparação para concluírem o curso técnico, e já estão sendo orientados em seus Trabalhos de Conclusão de Curso (TCC), sob orientação de professores do Curso Técnico em Recursos Pesqueiros, Campus Macau, ou elaboração de relatório de atividade profissional em empresas do ramo pesqueiros ou aquícola.

Ao longo destes dois anos de curso técnico em Recursos Pesqueiros, acredita-se que, para um bom acompanhamento das disciplinas ministradas aos alunos com faixa etária considerada vida adulta média (30 a 50 anos), e vida adulta tardia ou segunda vida adulta (50 a 65 anos), faixa etária bem comum na modalidade EJA, com a qual o referido curso também é contemplado é interessante o despertar desses alunos, envolvendo-os com atividades em que possam ser os protagonistas do processo de aprendizagem/aperfeiçoamento, ao analisar o déficit adquirido ainda na escola pública, ou mesmo pelos longos anos longe de uma sala de aula.

Desta forma, pode-se incentivar a motivação em estar numa escola pública de qualidade, com recursos didáticos acessíveis a todos, e garantindo enriquecimento do setor de onde muitos provêm.

Foi notado através do contato direto com esta turma, que um dos problemas de relacionamento entre seus integrantes e os diversos professores do curso, enfim seu relacionamento interpessoal se dá não necessariamente devido aos problemas encontrados nas escolas de ensino fundamental e médio, sejam das instâncias municipal ou estadual, mas também devido a sua origem familiar, e do convívio sociocultural da comunidade onde vivem, proporcionando um caminho para investigações futuras em relação à abordagem sociocultural, analisando o aluno não apenas como um ser profissional, mas principalmente, um ser social. 


\section{CONSIDERAÇÕES FINAIS}

A partir das análises feitas com os alunos da turma envolvida na pesquisa, conclui-se o seguinte:

- turma de alunos com as faixas etárias heterogêneas dos alunos podem tornar mais complexo o aprendizado em sala de aula, principalmente quando relacionado ao tempo de afastamento desta;

- a baixa qualidade do ensino propedêutico ofertado pelas escolas públicas estaduais e municipais do Rio Grande do Norte, basicamente no município de Macau;

- aulas de campo incentivam ao aprendizado, a partir de relatos próprios dos alunos;

- a importância de atividades práticas em sala de aula, e também em laboratórios, tais como as usadas na modalidade subsequente, também serem usadas na modalidade EJA, a fim de motivar e ressignificar a aprendizagem.

- os princípios andragógicos são reconhecidos nas turmas de jovens e adultos, uma vez que se necessita de práticas mais condizentes às fases complexas de vida dos alunos.

Cabe ressaltar que, apesar desses entraves, os alunos se sentem motivados ao curso e à instituição devido à qualidade do ensino e dos professores.

\section{REFERÊNCIAS BIBLIOGRÁFICAS}

1. BRASIL. Ministério da Educação. Instituto Federal de Educação, Ciência e Tecnologia do Rio Grande do Norte - IFRN. Disponível em: < http://www.ifrn.edu.br/secoes/processosseletivos/tecnico-subsequente/?searchterm $=$ modalidade\%20subsequente $>$. Acesso em: 10 mai. 2010, 11:09.

2. GOMES, C.O; ANGELO, C.B; MOURA, D. H. Do discurso oficial à realidade: conhecendo os estudantes do proeja. In: SILVA, Amélia Cristina Reis e; BARACHO, Maria das Graças (Orgs). Formação de educadores para o PROEJA: intervir para integrar. Natal: Cefetrn, 2007.p.119135.

3. GATTI, P. I. A andragogia na educação à distância: uma concepção de ensino utilizada na educação corporativa. 2005. Monografia apresentada ao Curso de Especialização em Informática na Educação - da Universidade Estadual de Londrina.

4. GRIFFA, M.C, MORENO, J.E. Chaves para a psicologia do desenvolvimento, tomo 2: adolescência, vida adulta, velhice. 4a edição - São Paulo: Paulinas, 2009.

5. LOPES, J.;VALENTIM, S. dos S. Educação profissional integrada a EJA: a produção intelectual sobre o currículo integrado. Disponível em:

<http://www.senept.cefetmg.br/galerias/Arquivos_senept/anais/terca_tema6/TerxaTema6A rtigo6.pdf.> Acesso em: 05 abr. 2010, 12:20.

6. ZABALA, A. Enfoque globalizador e pensamento complexo: uma proposta para o currículo escolar. Trad. Ernani Rosa. Porto Alegre, Artmed, 2002. 